\title{
AMMA-MODEL \\ INTERCOMPARISON PROJECT
}

by Frédéric Hourdin, lonela Musat, Françoise Guichard, Paolo Michele Ruti, Florence Favot, Marie-Angèle Filiberti,* Maï Pham, Jean-Yves Grandpeix, Jan Polcher, Pascal Marquet, Aaron Boone, Jean-Philippe Lafore, Jean-Luc Redelsperger, Alessandro Dell'aquila, Teresa losada Doval, Abdoul Khadre Traore, and Hubert Gallée

A meridional cross-section analysis provides the framework to assess regional and global model skill at simulating seasonal and intraseasonal variations of the West African monsoon, and thus mechanisms for the region's rainfall.

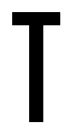

HE AMMA-MIP BACKGROUND. The African monsoon is characterized by a well-defined meridional structure of surface albedo and vegetation (Fig. 1a), with relatively weaker longitudinal variations. This structure is tightly connected to that of the mean rainfall (Fig. 1b), with maximum rainfall occurring in the Sudanian region $\left(10^{\circ}-13^{\circ} \mathrm{N}\right)$ during the northern summer. In addition, there is a sharp transition over the Sahel $\left(13^{\circ}-18^{\circ} \mathrm{N}\right)$, which is a particularly sensitive region that experienced a significant drought in the late 1970s and 1980s (Hulme 1992).

FIG. I. (a) A satellite-based image of West African surface albedo [source: European Organisation for the Exploitation of Meteorological Satellites (EUMETSAT); www.eumetsat.int/ HOME/Main/Access_to_Data/Meteosat Meteorological_Products/Product_List/ SP_II25489019643, Pinty et al. (2005)] and (b) GPCP accumulated rainfall for the year $2000(\mathrm{~mm})$. The red rectangle corresponds to the zone retained for the AMMA-CROSS section, and the green rectangles corresponds to the mesoscale AMMA sites.
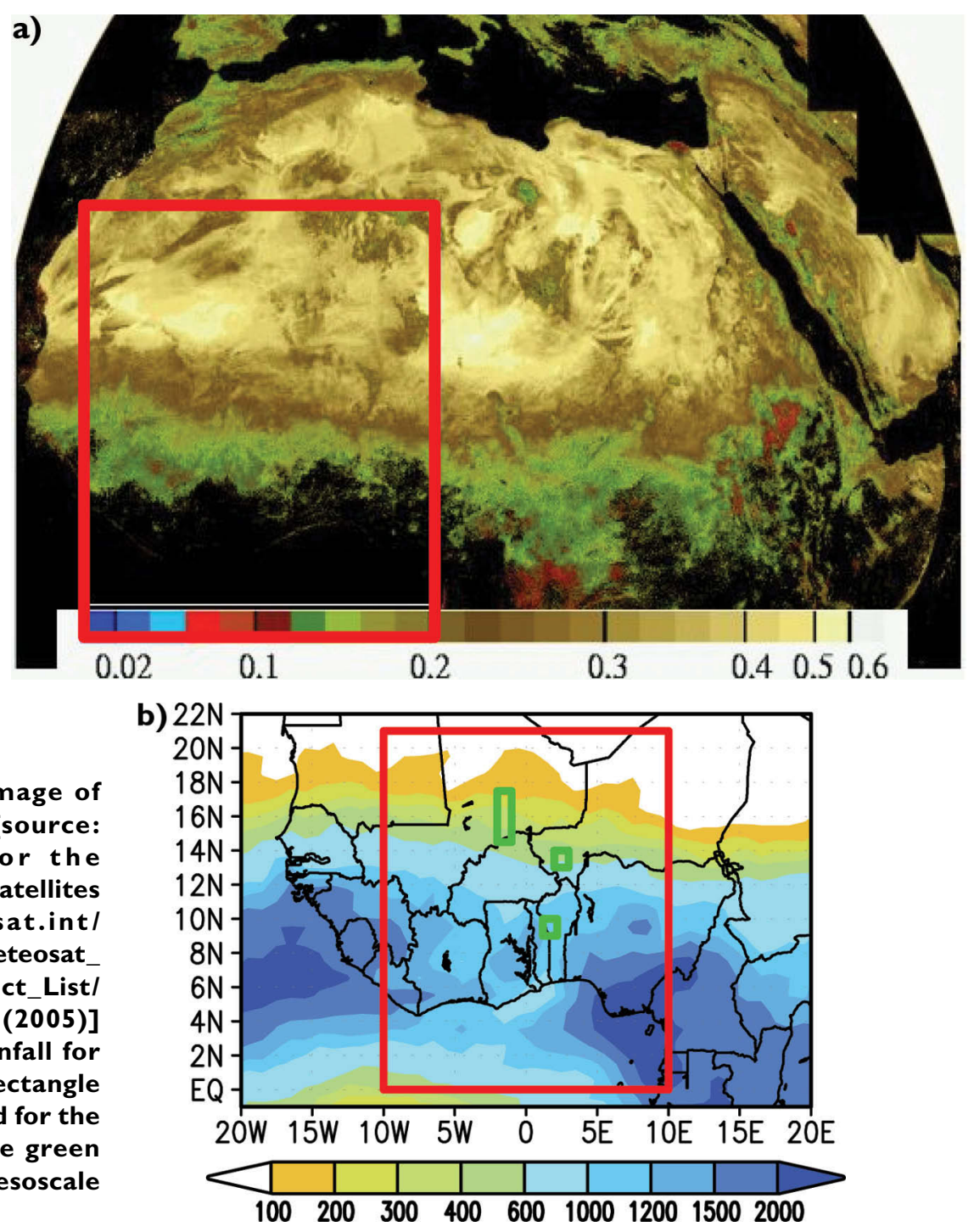
The meridional structure of the mean rainfall is itself related to the mean meridional circulation (Fig. 2), characterized by a nearsurface monsoon flow that brings water evaporated over the Gulf of Guinea over the African continent. This monsoon flow converges with a southward dry airflow coming from the Sahara at the "intertropical discontinuity" in the region of the Saharan heat low where dry convection occurs. The return branch of this Hadley circulation at around $600 \mathrm{hPa}$ is associated through the angular momentum budget and thermal wind balance with the African easterly jet (AEJ), which, in turn, transports additional moisture from the Indian Ocean. The intertropical convergence zone (ITCZ) is positioned at around $10^{\circ} \mathrm{N}$, where most of the convective rainfall occurs, with a mean upward motion that reaches $200 \mathrm{hPa}$ where the tropopause easterly jet is located.

The relative zonal symmetry of the climate means does not account for the strong longitudinal variations taking place on a daily basis. The accumulated rainfall is the result of successive convective events, which are either local or organized as mesoscale con-

AfFiliations: Hourdin, Musat, Grandpeix, and PolcherLMD/IPSL, UPMC, Paris, France; GuICHARD, FAVOt, MARQUeT, Boone, LAFore, AND RedelsPerger-CNRM/GAME (CNRS and Météo-France), Toulouse, France; Ruti AND DeLL'AQUILA-ENEA, Rome, Italy; PHAM—SA/IPSL, UPMC, Paris, France; LOSADA Doval-Departamento de Geofisica y Meteorologia, Facultad de Ciencias Fisicas, UCM, Madrid, Spain; TRAORE-LPAOSF, UCAD, Dakar, Senegal; GalléE-LGGE, CNRS, Grenoble, France *Deceased.

CORRESPONDING AUTHOR: Frédéric Hourdin, Laboratoire de Météorologie Dynamique du CNRS, UPMC, $\operatorname{Tr} 45-55$, 3et, BP 99, 75252 Paris CEDEX 05, France

E-mail: hourdin@Imd.jussieu.fr

The abstract for this article can be found in this issue, following the table of contents.

DOI:10.1175/2009BAMS279I.I

In final form 29 June 2009

(C)2010 American Meteorological Society vective systems or squall lines (Mathon et al. 2002). The interaction between the tropical waves and the convection plays a dominant role at both synoptic (the main convective activity typically develops ahead of or within the trough of the African easterly waves) and intraseasonal (very important for agriculture) time scales. At intraseasonal and interannual time scales, the African monsoon is also influenced by regional and global patterns of the sea surface temperature (SST) and local coupling with surface processes, but the amplitude and mechanisms of those couplings are still very uncertain.

The last Intergovernmental Panel on Climate Change (IPCC) report (Solomon et al. 2007) confirms that coupled atmosphere-ocean models poorly simulate the West African climate (Cook and Vizy 2006). As for climate change projections, the models disagree even on the sign of the expected trend in the mean rainfall on that region. Atmospheric models forced by observed SSTs also fail to reproduce some important aspects of the monsoon system.

The African Monsoon Multidisciplinary Analyses (AMMA) project was designed in a large part to address the main uncertainties in atmospheric processes controlling the monsoon system and to contribute to the evaluation and improvement of climate and weather forecast models in that respect. The observational strategy included both reinforcement of the operational network of surface stations and of 
soundings on a long-term basis, and an intensive field campaign during the monsoon (northern summer) season in 2006 (Redelsperger et al. 2006). Recognizing the meridional stratification of the monsoon system, a large part of the observations were focused on a latitudinal transect located at approximately $0^{\circ}$ longitude, in particular over Benin, Niger, and Mali. Three "mesoscale sites," corresponding to three typical climates, were equipped to document the landatmosphere interactions along the transect.

The coordinated intercomparison and evaluation of global and regional atmospheric models started at the beginning of the AMMA project. This led to the creation of AMMA-Model Intercomparison Project (AMMA-MIP), a light, focused, and process-oriented intercomparison exercise. The models, either global or regional, are evaluated in terms of their ability to reproduce the mean West African climate and, in particular, the seasonal and intraseasonal variations of rainfall and associated dynamical structures.

The exercise is "light" in the sense that the modeling teams are only requested to provide relevant subsets of the full model outputs made available on an FTP site. A parallel effort is also carried out for observational datasets. A series of graphics are made available through a Web interface (http://amma-mip. Imd.jussieu.fr). In this sense, AMMA-MIP is more comparable to exercises organized within the framework of the Global Energy and Water Cycle Experiment (GEWEX) Cloud System Study (GCSS) groupsuch as the eastern Pacific cross section (Siebesma et al. 2004) - than to the classical model intercomparison projects developed in the climate community.

The design of the AMMA-MIP is presented herein. Next, some results for two contrasting years (2000 and 2003) are shown, which were selected prior to the campaign. This first intercomparison is also aiding in the preparation for the next phase of this project, which will include the 2006 intensive field campaign experiment.

THE AMMA-MIP STATUS. AMMA-MIP design. AMMA-MIP is made of two parts, corresponding to two types of output files, both of which are provided at daily frequency for a full seasonal cycle. (For those who would like to contribute, a full description of AMMA-MIP is available online at http://amma-mip. Imd.jussieu.fr/description.html.)

The first part, the AMMA cross section (AMMACROSS), is a latitude-altitude cross section made of $10^{\circ} \mathrm{W}-10^{\circ} \mathrm{E}$ zonally averaged variables (red boxes in Fig. 1) over the region of $20^{\circ} \mathrm{S}-40^{\circ} \mathrm{N}$. AMMACROSS is focused on the latitudinal extent of the
West African monsoon system, the jumps and breaks of the monsoon rainfall, and their relation with, in particular, the mean meridional circulation, the penetration of the monsoon flow, and the strength of the Saharan heat low or the surface fluxes. The idea of the cross section is inherited from the Pacific cross section mentioned earlier. It also has been found to be a suitable framework for more academic investigations (e. g., Zheng and Eltahir 1998; Peyrillé et al. 2007).

In the second part, AMMA-MAPS, a subset of variables (on a few standard pressure levels for 3D fields) are provided over the region $10^{\circ} \mathrm{S}-30^{\circ} \mathrm{N}, 35^{\circ} \mathrm{W}-$ $30^{\circ} \mathrm{E}$. The focus of AMMA-MAPS is on the African easterly jet and easterly waves, in conjunction with rainfall, the location of convection, and surface fluxes or orography.

The exercise is focused on the atmospheric component and its coupling with continental surfaces. Only atmospheric models with imposed SSTs are considered, because the biases of coupled models are generally related to large biases of the SST. Therefore, they are not suitable for regional studies over West Africa. Years 2000 (a dry summer during which the JET2000 campaign was conducted; Thorncroft et al. 2003) and 2003 (a wetter year) were selected for a first approach.

Models involved. So far, six teams have contributed to the AMMA-MIP. Four global models are involved: Action de Recherche Petite Echelle Grande Echelle (ARPEGE)-Climat, run at the Centre National de Recherches Météorologiques (CNRM), ECHAM4, run at the Italian National Agency for New Technologies, Energy and Sustainable Economic Development (ENEA; Ruti et al. 2006), the University of California, Los Angeles, version 7.3 (UCLA7.3) GCM (Mechoso et al. 2000), run at the Universidad Complutense de Madrid (UCM), and the Laboratoire de Météorologie Dynamique model (LMDZ4), run at the L'Institut Pierre-Simon Laplace (IPSL; Hourdin et al. 2006). A limited-area simulation with Modèle Atmosphérique Régional (MAR; Gallée et al. 2004) was provided by the Laboratoire de Glaciologie et Géophysique de l'Environmement (LGGE). The LMDZ4 model is also run with a refined grid over West Africa (zoom) that provides another approach to regional climate modeling. Two configurations of this zoomed version are tested at IPSL and the Laboratoire de Physique de l'Atmosphère et de l'Océan Simeon Fongang (LPAOSF). (Descriptions of the various models are available at http://amma-mip.Imd.jussieu. fr/MODELS/Welcome.html.) Two teams provided ensemble simulations of 5 (IPSL) and 10 (UCM) 
members, respectively, performed with the same boundary conditions but different initial states. Two teams also provided sensitivity experiments to model parameterized convection [LMDZ was run at IPSL either with the Tiedtke (1989) convection scheme or with the Emanuel (1993) convection scheme] and vertical resolution (ECHAM4 was run at ENEA with 19 or 42 layers). Additional details on the model configurations are given in Table 1.

Observations. An effort has been carried out in parallel with respect to observational products, and the most relevant sources of data have been identified. As was done for the simulation outputs, the observations are preprocessed in the form of mean cross section $\left(10^{\circ} \mathrm{W}-10^{\circ} \mathrm{E}\right)$ on the one hand and $2 \mathrm{D}$ horizontal maps on the other (data are available by anonymous ftp at cnrm-ftp.meteo.fr in the pub-moana/amma-cross directory.)

Here we used the Global Precipitation Climatology Project (GPCP; daily and $1^{\circ}$ resolution; Huffman et al. 1997) and the Climate Prediction Center Merged Analysis of Precipitation (CMAP; pentad, monthly, and $2.5^{\circ}$ resolution; Xie and Arkin 1997) rainfall climatologies, and the following various reanalysis products available: National Centers for Environmental Prediction-National Center for Atmospheric Research (NCEP-NCAR) 40-yr Reanalysis (Kalnay et al. 1996), NCEP/Department of Energy Global Reanalysis 2 (NCEP-2; Kanamitsu

TABLE I. Details on the AMMA-MIP model configurations are given together with some diagnostics. The simulations are titled with the name of the corresponding institute followed by the number of the run for the ensemble runs or by the number of vertical levels for the ENEA runs. Most models use the AMIP SSTs (Taylor et al. 2000) except for ARPEGE, which uses the Reynolds Olv2 weekly SSTs (Reynolds et al. 2002) and the MAR model, which uses the SST derived from ECMWF operational analysis (ECOA). For the various models, we show for the JJAS season of year 2000: the AEJ latitude; the zonal wind root-mean-square error when compared with ERA-40; the mean rainfall over a West African box $\left(0^{\circ}-18^{\circ} \mathrm{N}, 10^{\circ} \mathrm{W}-10^{\circ} \mathrm{E}\right)$, a Sahelian box $\left(13^{\circ}-18^{\circ} \mathrm{N}, 10^{\circ} \mathrm{W}-10^{\circ} \mathrm{E}\right)$, a Sudanian box $\left(10^{\circ}-13^{\circ} \mathrm{N}, 10^{\circ} \mathrm{W}-10^{\circ} \mathrm{E}\right)$, a continental Guinean box $\left(5^{\circ}-10^{\circ} \mathrm{N}, 10^{\circ} \mathrm{W}-10^{\circ} \mathrm{E}\right)$, and a Gulf of Guinea box $\left(0^{\circ}-5^{\circ} \mathrm{N}, 10^{\circ} \mathrm{W}-10^{\circ} \mathrm{E}\right)$ for all of the AMMA-MIP simulations and observation datasets. For the IPSL and UCM ensemble runs, we show the lowermost and the uppermost limit within the members. For the observed AEJ latitude, the first number corresponds to ERA-40 and the second to the maximum latitude between the NCEP-NCAR and NCEP-2 reanalyses. For the "observed" zonal wind rms, the two values correspond to NCEP-NCAR and NCEP-2 reanalyses compared with ERA-40. For the observed rainfall, the two values correspond to th GPCP and CMAP datasets.

\begin{tabular}{|c|c|c|c|c|c|c|c|c|c|}
\hline Institute & CNRM & ENEA & UCM & IPSL & IPSLTI & IPSLWA & LPAOSF & LGGE & Obs. \\
\hline Model & ARPEGE & ECHAM4 & UCLA7.3 & LMDZ4 & LMDZ4 & LMDZ4 & LMDZ4 & MAR & - \\
\hline Mesh size $(\mathrm{km})$ & 300 & 370 & 220 & 300 & 300 & 80 & 140 & 40 & - \\
\hline No. layers & & & & & & & & & \\
\hline total & 31 & $19-42$ & 29 & 19 & 19 & 19 & 19 & 40 & - \\
\hline Surface-800 hPa & 7 & $5-11$ & 3 & 5 & 5 & 5 & 5 & II & - \\
\hline $800-200 \mathrm{hPa}$ & 15 & $7-18$ & 9 & 6 & 6 & 6 & 6 & 28 & - \\
\hline SST & Reynolds & AMIP & AMIP & AMIP & AMIP & AMIP & AMIP & ECOA & 一 \\
\hline Specificity & $\begin{array}{l}\text { climate } \\
\text { version }\end{array}$ & $\begin{array}{l}2 \text { vertical } \\
\text { resolution }\end{array}$ & $\begin{array}{c}\text { Ensemble } \\
(10)\end{array}$ & $\begin{array}{c}\text { Ensemble } \\
\text { (5) }\end{array}$ & $\begin{array}{c}\text { Convection } \\
\text { Tiedtke } \\
\text { versus } \\
\text { Emanuel }\end{array}$ & $\begin{array}{l}\text { Zoom } \\
\text { West } \\
\text { Africa }\end{array}$ & $\begin{array}{l}\text { Zoom } \\
\text { West } \\
\text { Africa }\end{array}$ & $\begin{array}{l}\text { Limited } \\
\text { area } \\
\text { ECOA } \\
\text { Boundary }\end{array}$ & - \\
\hline \multicolumn{10}{|c|}{ JJAS mean zonal wind } \\
\hline AEJ lat $\left({ }^{\circ} \mathbf{N}\right)$ & 13.3 & $12.9-14.8$ & $15.2-15.8$ & $10.9-12.5$ & 11.6 & 16.1 & $13.6-13.9$ & 13.1 & $12.8-12.2$ \\
\hline RMS error $\left(\mathrm{m} \mathrm{s}^{-1}\right)$ & 4.4 & $3.8-4.6$ & $4.1-4.4$ & $3.5-3.8$ & 3.8 & 4.5 & $4.0-4.2$ & 3.2 & $2.9-3.0$ \\
\hline \multicolumn{10}{|c|}{ JJAS mean rainfall ( $\mathrm{mm}$ day $\left.^{-1}\right)$} \\
\hline West Africa & 3.0 & $3.4-3.0$ & $5.6-6.0$ & $2.6-3.0$ & 3.2 & 5.3 & $4.6-4.3$ & 5.9 & $4.2-4.4$ \\
\hline Sahel, $13^{\circ}-18^{\circ} \mathbf{N}$ & 1.8 & $2.6-2.2$ & $5.7-6.0$ & $0.8-1.1$ & 0.6 & 4.5 & $2.7-2.4$ & 2.6 & $2.2-2.8$ \\
\hline Sudan, $10^{\circ}-13^{\circ} \mathrm{N}$ & 4.4 & $4.9-4.4$ & $9.9-10.4$ & $3.3-3.9$ & 3.6 & 8.9 & $7.0-6.5$ & 8.0 & $5.1-6.6$ \\
\hline Guinea, $5^{\circ}-10^{\circ} \mathrm{N}$ & 4.6 & $5.0-4.2$ & $5.8-6.4$ & $5.3-6.2$ & 7.2 & 7.6 & $7.8-7.5$ & 8.8 & $6.2-6.4$ \\
\hline Atlantic, $0^{\circ}-5^{\circ} \mathrm{N}$ & 1.8 & $1.8-1.7$ & $2.5-2.9$ & $1.1-1.3$ & 1.6 & 1.5 & $1.7-1.7$ & 5.1 & $3.6-2.8$ \\
\hline
\end{tabular}


et al. 2002), 40-yr European Centre for MediumRange Weather Forecasts (ECMWF) Re-Analysis (ERA-40; Uppala et al. 2005), and ERA-Interim (Simmons et al. 2006).

AMMA-MIP: FIRST RESULTS. Preliminary results presented here illustrate 1) the current skill of atmospheric models to reproduce the African monsoon; 2) the relevance of the AMMA-MIP framework; and 3) the strategy foreseen for the use of the AMMA observations. Additional results are available on the AMMA-MIP Web site.

Mean dynamical structure. The June-September (JJAS) conditions for AMMA-CROSS mean zonal wind are presented for the AMMA-MIP models and for NCEP-2 and ERA-40 in Fig. 3. The various models capture the main elements of the zonal circulation, such as the westerlies (positive contours and red colors) near the surface within the monsoon flow (equator $-20^{\circ} \mathrm{N}$ ) or the predominance of easterlies in the midtroposphere. However, important differences are observed. The monsoon flow is too strong for some simulations [IPSL model using the Tiedke convection scheme (IPSLTI), CNRM, UCM, and LGGE] and is somewhat too weak for others [ENEA model run with 19 vertical layers (ENEAL 19) and 42 vertical layers (ENEAL42)]. ENEA, IPSL, and LGGE correctly simulate an isolated AEJ. Differences are also seen above $400 \mathrm{hPa}$, with, for instance, too strong westerlies in the ENEA simulations. Those differences are quantified for all the simulations in Table 1 by computing the root-mean-square difference between the mean JJAS zonal wind over the cross section and that obtained in ERA-40 for the year 2000.

The comparison between the two ENEA simulations gives an idea of the effect of the vertical resolution; the comparison of IPSL1-IPSLTI documents the major effect of parameterized convection, whereas that of UCM1 and UCM2 illustrate the internal (not forced by SST variability) interannual variability as produced by GCMs. LPAOSF, IPSL model run with a

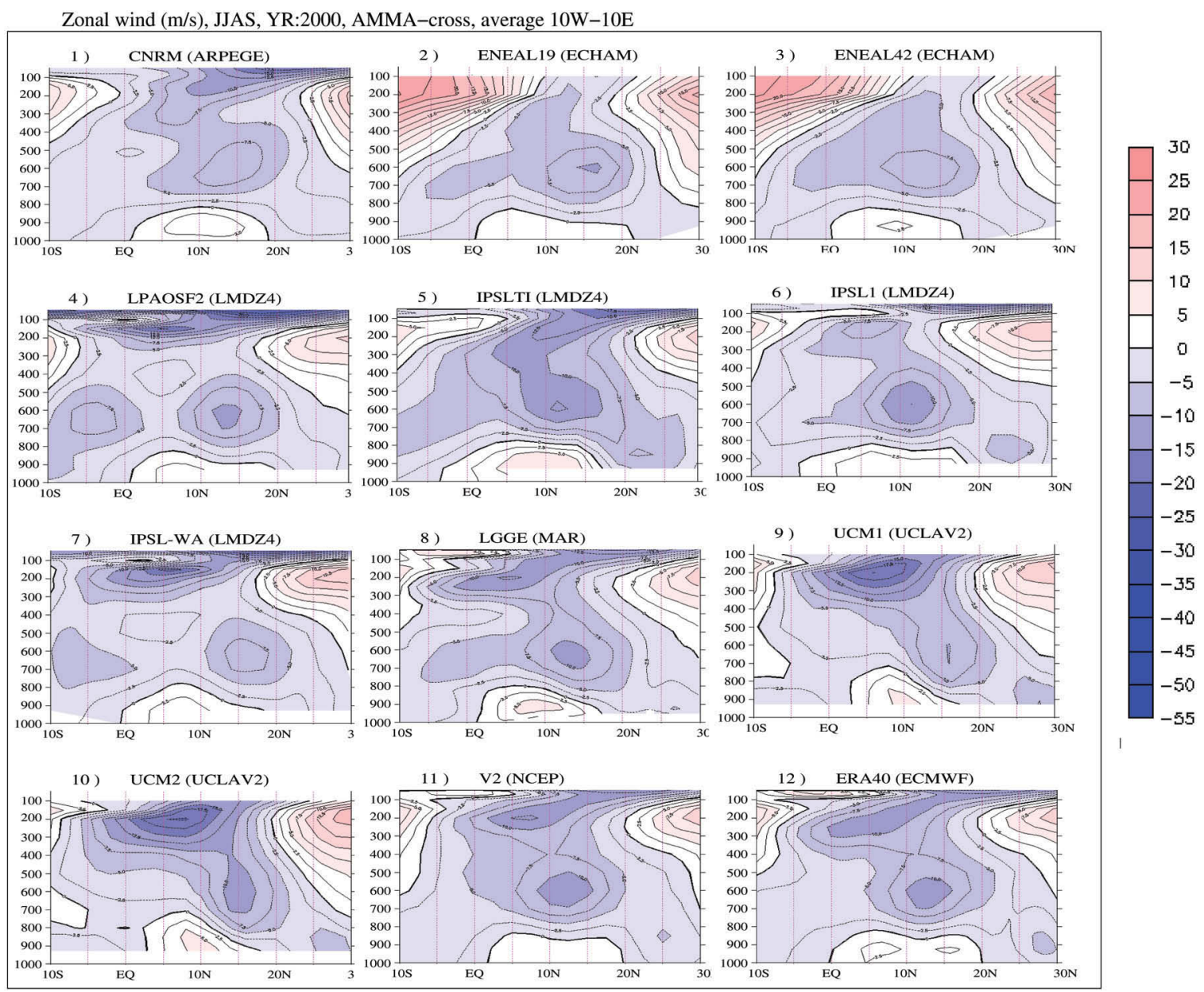

Fig. 3. Latitude-pressure cross section (averaged between $10^{\circ} \mathrm{W}$ and $10^{\circ} \mathrm{E}$ ) of the zonal wind $\left(\mathrm{m} \mathrm{s}^{-1}\right)$ for the various configurations (see Table I) and for NCEP-2 and ERA-40 reanalyses; year 2000, JJAS. 
precipitation, Seasonal Cycle, YR:2000, AMMA-cross, average 10W-10E
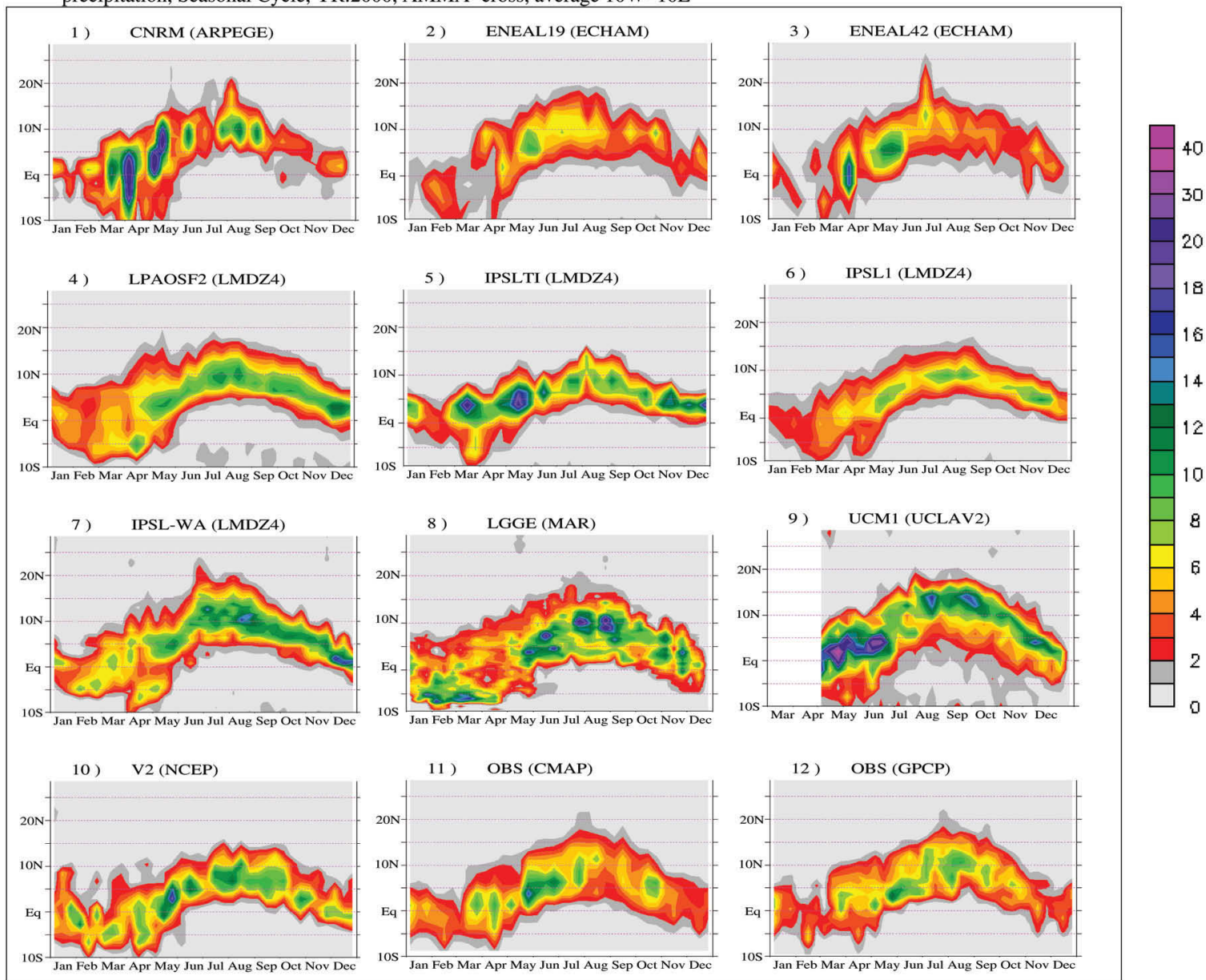

FIG. 4. The seasonal evolution of the 10 -day running mean of the $10^{\circ} \mathrm{W}-10^{\circ} \mathrm{E}$ averaged rainfall $(\mathrm{mm}$ day $^{-1}$ ) for simulations CNRM, ENEALI9, ENEAL42, LPAOSF2, IPSLTI, IPSL1, IPSLWA, LGGE, and UCM1, as well as for NCEP-2 reanalysis, CMAP and GPCP observations; year 2000.

zoom over West Africa (IPSLWA), and IPSL1 are run with LMDZ4 model versions that are very similar but have different horizontal grids.

Rainfall. A comparison of the seasonal cycle of rainfall is shown in Fig. 4 for the year 2000. The simulations displayed are the same as those in Fig. 3. The models generally capture the latitudinal migration of the ITCZ from south of the equator over the ocean (the Guinean coast is located at about $5^{\circ} \mathrm{N}$ ) during northern winter to West Africa during the monsoon season.

However, the rainfall intensity over the Sahel (around $15^{\circ} \mathrm{N}$ in Fig. 4 ) is very different in the various models. The simulated mean rainfall rate for JJAS over the Sahel box in Table $1\left(13^{\circ}-18^{\circ} \mathrm{N}, 10^{\circ} \mathrm{W}-10^{\circ} \mathrm{E}\right)$ varies from 0.6 (IPSLTI) to $6 \mathrm{~mm} \mathrm{day}^{-1}$ (UCM). Over the Guinean Gulf, most models underestimate the rainfall; only one model is giving about the right value (UCM) and one model clearly overestimates it (LGGE). All of the models show active sequences and breaks, although the intraseasonal variability is probably too weak in some models (LPAOSF) and too strong in others (CNRM; not shown).

The rainfall and dynamical structures are expected to be related. In particular, the accumulated rainfall over the Sahelian band is expected to be related to the depth of the penetration of the monsoon flow toward the Sahara, and potentially to the position of the easterly jet and easterly waves, which are known to modulate the convective activity over Sahel.

A positive correlation between the AEJ core latitude ${ }^{1}$ and the Sahelian mean rainfall is indeed visible in the

${ }^{1}$ The AEJ core latitude is defined here as a weighted latitude in the region where the zonal wind is $\delta u\left(2 \mathrm{~m} \mathrm{~s}^{-1}\right)$ larger than the minimum value $\int_{5 N}^{24 N} \max \left(u_{\min }+\delta u-u, 0\right) \phi d \phi / \int_{5 N}^{24 N} \max \left(u_{\min }+\delta u-u, 0\right) d \phi$. The computation is done at the pressure level of the jet maximum. 


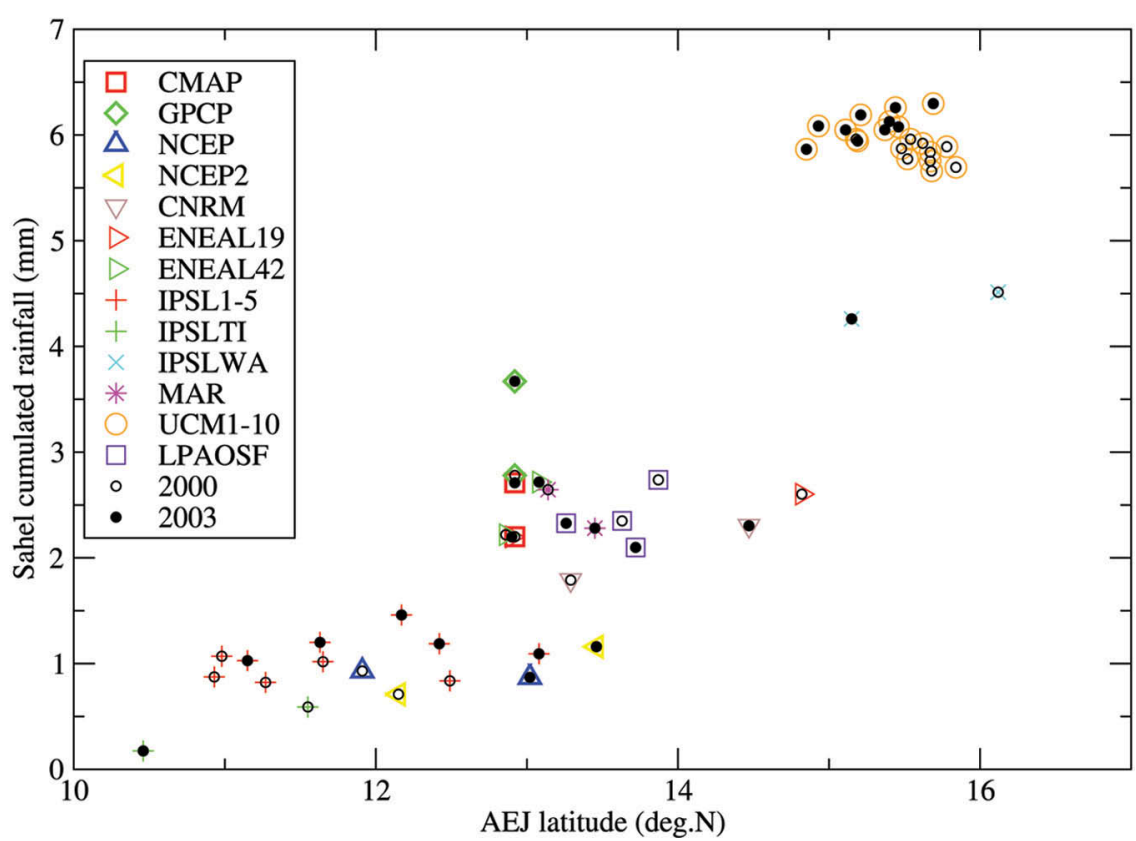

FIG. 5. Latitude of $A E J\left({ }^{\circ} N\right)$ versus mean rainfall over a Sahelian box $\left(13^{\circ}-18^{\circ} \mathrm{N}\right.$, $10^{\circ} \mathrm{W}-10^{\circ} \mathrm{E}$ ) for all of the AMMA-MIP simulations; for the CMAP and GPCP observations; and NCEP-NCAR, and NCEP-2 reanalyses for JJAS season, and 2000 (empty circle) and 2003 (filled circle) years. The AEJ latitude for CMAP and GPCP corresponds to the ERA-40 reanalyses for year 2000 and to ERA-Interim reanalyses for year 2003.

multimodel multirun AMMA-MIP database, as illustrated in Fig. 5, which suggests that a large part of the biases comes from a shift in the whole monsoon system in latitude. For a particular model configuration (see figure), the dispersion either as a result of the internal variability (as given by the ensemble runs when available) or the boundary conditions [2000 (empty circles) versus 2003 (filled circles) SSTs] is generally smaller than the typical difference between two models or between one model and observations. This can be assessed further by looking at the results in Table 1 .

Most simulations show a somewhat larger rainfall when forced by 2003 rather than by 2000 SSTs. However, the difference is not much larger than the internal variability given by the UCM and IPSL ensemble simulations for given SST conditions, suggesting that even the larger observed rainfall in 2003 could be due to internal variability rather than being forced by SSTs. The NCEP-NCAR reanalysis and ERA-40 suggest a jet farther north by about $1^{\circ}$ in 2003 (Grist and Nicholson 2001); however, no systematic correlation is found between a northward migration of the jet and larger rainfall in 2003 with respect to 2000 when looking at the models. It must be kept in mind that a displacement by $1^{\circ}$ is a displacement by less than one grid point for most models and reanalysis products.
Notice also that the reanalyses are in rather good agreement with each other for the jet core location but are quite far from observation for the Sahelian accumulated rainfall, making the reanalysis similar to rather bad climate models in that respect.

Surface fluxes. The latitudinal gradients of moist static energy have been shown to play a key role in the control of the African monsoon (Eltahir and Gong 1996). This latitudinal gradient is forced at first order by the thermal contrasts between the Gulf of Guinea (which is relatively cool at that time) and the Sahara. The aerosols and clouds significantly modulate the latitudinal contrasts of top of the atmosphere and surface radiative fluxes. The surface albedo can be an important source of discrepancy between the various models. Surface hydrology also plays a key role through the partitioning of sensible and latent heat fluxes (e.g., Fontaine et al. 2002).

Validation of climate models in terms of surface fluxes is one of the expected important outcomes of the campaign. Data are currently being processed in a form usable for model validation. In addition to direct observations, the AMMA Land Surface Model Intercomparison Project (ALMIP; Boone et al. 2009) provides a collection of simulated surface fields built using so-called soil-vegetation-atmosphere transfer models forced by a combination of observed, satellitebased, and forecast meteorological fields.

First analyses (not shown) revealed the large dispersion between the various AMMA-MIP models in terms of cloud forcing, and latent and sensible heat fluxes, a point which merits further investigations.

Parameterized convection and meridinal transport. The parameterized convection is a key issue for climate modeling, in particular over tropical continents. This aspect is illustrated based on results of the LMDZ4 model with the two deep convection schemes (corresponding to simulations IPSL1 and 
IPSLTI in Fig. 3). With the Emanuel (1993) convective scheme (Fig. 6), the convective heating [Fig. 6b, contours $\left.\left(\mathrm{K} \mathrm{day}^{-1}\right)\right]$ peaks higher up in the atmosphere, with stronger heating rates than for the Tiedtke (1989) scheme. The cooling (dashed contours) in the lower atmosphere over Sahel due to the evaporation of convective rainfall is also stronger with Emanuel. Those differences have a strong effect on the large-scale dynamics: the African easterly jet (Fig. 6a, colors) is much better represented with the Emanuel scheme (shown in Fig. 3); in the ITCZ region $\left(5^{\circ}-15^{\circ} \mathrm{N}\right)$, the ascent of the mean meridional circulation (streamlines) penetrates much higher in the Emanuel case. Notice that part of the changes obtained over West Africa may come from the effect of the convective scheme at larger scales, such as for the upper-level easterlies. The relative humidity

(Fig. 6b, colors) shows a signature of this different transport with, in particular, a local maximum that is stronger and higher in the ITCZ for the Emanuel scheme. An additional interest of the AMMA campaign for model evaluation is the joint observation of atmospheric composition and dynamics. The links between composition and dynamics is illustrated for carbon monoxide (CO) with the climate-chemistry model LMDZ-Interaction of Chemistry and Aerosols (INCA; Hauglustaine et al. 2004) as well as with an idealized tracer emitted in the boundary layer (between the surface and $850 \mathrm{hPa}$ ) over the African continent south of $10^{\circ} \mathrm{N}$, experiencing a radioactive decay with a lifetime of a few days (Fig. 6c). Tracers are pumped higher by the more penetrative Emanuel scheme, consistent with what is seen in the other panels. On the basis of those considerations, it was decided to extend the AMMA-CROSS framework to the intercomparison of chemistry transport models and coupled chemistry-climate models, comparing both realistic chemical tracers and tracers emitted in latitude bands close to the surface, either over the continent or the ocean.

CONCLUSIONS AND EXTENSION. Some conclusions can been retained from this first phase of the AMMA-MIP exercise:

1) Climate models, when forced by observed SSTs, succeed in simulating the main characteristics of the West African monsoon as the AEJ and the latitudinal migration of the rainfall band with the season.

2) However, huge errors remain when looking in more detail.

3) The accumulated rainfall over Sahel, one key variable in terms of social effect, varies by a factor of 10 for the models available in the database. 
4) The accumulated rainfall over Sahel is not better represented in the available reanalysis (NCEP-2 or ERA-40) than in current climate models.

5) A larger rainfall over Sahel is generally associated with an AEJ location farther north, suggesting that part of the discrepancies come from a general shift of the whole system in latitude.

6) The parameterized convection has also a major effect.

7) No model is able to simulate correctly all the aspects of the monsoon system (ECHAM4 shows probably the best compromise at this stage.).

8) The model-specific bias errors for Sahel rainfall, dynamical structures, or surface fluxes are consistent across the year, completely overwhelming interannual differences in the experiments. This is a strong argument for supporting the value of the AMMA field campaign-focused on one particular year-to importantly constrain climate models.

The next phase of the AMMA-MIP exercise will focus on 2005/06, the year of the intensive phase of the AMMA field experiment (Janicot et al. 2008). Some model results are already available on the database. Contributions from other modeling teams are, of course, welcome. As for observations, particular care will be given to the compilation of AMMA soundings (classical soundings, dropsondes sent from aircrafts or balloons; Parker et al. 2008) and boundary fluxes measurements along the AMMA transect, obtained either from dedicated aircraft measurements or at the mesoscale sites with flux towers. The ALMIP database should also yield some clues to assess the representation of coupled processes at the surface.

The AMMA-MIP project, and in particular the AMMA cross-section analysis, provides a relevant framework for focusing on the climate feedbacks and on the interactions between climate components, such as atmosphere, land surface, and chemistry. It is a unique framework, allowing the study of the effect of different climatic components on the hydrological cycle, and it could be a good candidate for a GCSS. It is also envisaged for the future to analyze in the AMMA-MIP framework the simulations made available in the West African Monsoon Model Evaluation program. This framework may help evaluate the biases of numerical weather forecast models as well.

ACKNOWLEDGMENTS. On the basis of a French initiative, AMMA was built by an international scientific group and is currently funded by a large number of agencies, especially from France, the United Kingdom, the United States, and Africa. It has been the beneficiary of a major financial contribution from the European Community's Sixth Framework Research Programme. Detailed information on scientific coordination and funding is available on the AMMA International Web site (www. amma-international.org). NCEP-NCAR 40-yr reanalysis and NCEP-2 data were provided by the NOAA-CIRES Climate Diagnostics Center, Boulder, Colorado. GPCP data were provided by the NOAA/OAR/ESRL/PSD, Boulder, Colorado (www.cdc.noaa.gov). ERA-40 and ERA-Interim data used in this study/project have been obtained from the ClimServ IPSL data center (http://climserv.ipsl.polytechnique.fr/). The IPSL numerical simulations were performed on the NEC-SX8 of the IDRIS/CNRS computer center.

\section{REFERENCES}

Boone, A., and Coauthors, 2009: The AMMA Land Surface Model Intercomparison Project (ALMIP). Bull. Amer. Meteor. Soc., 90, 1865-1880.

Cook, K. H., and E. K. Vizy, 2006: Coupled model simulations of the West African monsoon system: Twentieth- and twenty-first-century simulations. J. Climate, 19, 3681-3703.

Eltahir, E. A. B., and C. Gong, 1996: Dynamics of wet and dry years in West Africa. J. Climate, 9, 1030-1042.

Emanuel, K. A., 1993: A cumulus representation based on the episodic mixing model: The importance of mixing and microphysics in predicting humidity. The Representation of Cumulus Convection in Numerical Models of the Atmosphere, Meteor. Monogr., No. 46, Amer. Meteor. Soc., 185-192.

Fontaine, B., N. Philippon, S. Trzaska, and P. Roucou, 2002: Spring to summer changes in the West African monsoon through NCEP/NCAR reanalyses (1968-1998). J. Geophys. Res., 107, 4186, doi:10.1029/2001JD000834.

Gallée, H., and Coauthors, 2004: A high-resolution simulation of a West African rainy season using a regional climate model. J. Geophys. Res., 109, 5108, doi:10.1029/2003JD004020.

Grist, J., and S. E. Nicholson, 2001: A study of the dynamic factors influencing the rainfall variability in the West African Sahel. J. Climate, 14, 1337-1359.

Hauglustaine, D. A., F. Hourdin, L. Jourdain, M.-A. Filiberti, S. Walters, J.-F. Lamarque, and E. A. Holland, 2004: Interactive chemistry in the Laboratoire de Météorologie Dynamique general circulation model: Description and background tropospheric chemistry evaluation. J. Geophys. Res., 109, D04314, doi:10.1029/2003JD003957. 
Hourdin, F., and Coauthors, 2006: The LMDZ4 general circulation model: Climate performance and sensitivity to parametrized physics with emphasis on tropical convection. Climate Dyn., 27, 787-813.

Huffman, G., and Coauthors, 1997: The Global Precipitation Climatology Project (GPCP) combined precipitation dataset. Bull. Amer. Meteor. Soc., 78, 5-20.

Hulme, M., 1992: Rainfall changes in Africa: 1931-1960 to 1961-1990. Int. J. Climatol., 12, 685-699.

Janicot, S., and Coauthors, 2008: Large-scale overview of the summer monsoon over West Africa during the AMMA field experiment in 2006. Ann. Geophys., 26, 2569-2595.

Kalnay, E., and Coauthors, 1996: The NCEP/NCAR 40-Year Reanalysis Project. Bull. Amer. Meteor. Soc., 77, 437-471.

Kanamitsu, M., W. Ebisuzaki, J. Woollen, S.-K. Yang, J. J. Hnilo, M. Fiorino, and G. L. Potter, 2002: NCEPDEO AMIP-II Reanalysis (R-2). Bull. Amer. Meteor. Soc., 83, 1631-1643.

Mathon, V., H. Laurent, and T. Lebel, 2002: Mesoscale convective system rainfall in the Sahel. J. Appl. Meteor., 41, 1081-1092.

Mechoso, C. R., J.-Y. Yu, and A. Arakawa, 2000: A coupled GCM pilgrimage: From climate catastrophe to ENSO simulations. General Circulation Model Development: Past, Present, and Future, D. A. Randall, Ed., International Geophysics Series, Vol. 70, Academic Press, 539-575.

Parker, D. J., and Coauthors, 2008: The AMMA radiosonde program and its implications for the future of atmospheric monitoring over Africa. Bull. Amer. Meteor. Soc., 89, 1015-1027.

Peyrillé, P., J.-P. Lafore, and J.-L. Redelsperger, 2007: An idealized two-dimensional framework to study the West African monsoon. Part I: Validation and key controlling factors. J. Atmos. Sci., 64, 2765-2782.

Redelsperger, J.-L., C. D. Thorncroft, A. Diedhiou, T. Lebel, D. J. Parker, and J. Polcher, 2006: African Monsoon Multidisciplinary Analysis: An international research project and field campaign. Bull. Amer. Meteor. Soc., 87, 1739-1746.
Reynolds, R., N. Rayner, T. Smith, D. Stokes, and W. Wang, 2002: An improved in situ and satellite SST analysis for climate. J. Climate, 15, 1609-1625.

Ruti, P. M., D. di Rocco, and S. Gualdi, 2006: Impact of increased vertical resolution on simulation of tropical climate. Theor. Appl. Climatol., 85, 61-80.

Siebesma, A. P., and Coauthors, 2004: Cloud representation in general-circulation models over the northern Pacific Ocean: A EUROCS intercomparison study. Quart. J. Roy. Meteor. Soc., 130, 3245-3267.

Simmons, A., S. Uppala, D. Dee, and S. Kobayashi, 2006: ERA-Interim: New ECMWF reanalysis products from 1989 onwards. ECMWF Newsletter, No. 110, ECMWF, Reading, United Kingdom, 25-35.

Solomon, S., D. Qin, M. Manning, M. Marquis, K. B. Averyt, M. M. B. Tignor, H. L. Miller Jr., and Z. Chen, Eds., 2007: Climate Change 2007: The Scientific Basis. Cambridge University Press, 996 pp.

Taylor, K. E., D. Williamson, and F. Zwiers, 2000: The sea surface temperature and sea-ice concentration boundary conditions for AMIP II simulations. Program for Climate Model Diagnosis and Intercomparison Rep. 60, 28 pp.

Thorncroft, C. D., and Coauthors, 2003: The JET2000 project: Aircraft observations of the African easterly jet and African easterly waves. Bull. Amer. Meteor. Soc., 84, 337-351.

Tiedtke, M., 1989: A comprehensive mass flux scheme for cumulus parameterization in large-scale models. Mon. Wea. Rev., 117, 1179-1800.

Uppala, S. M., and Coauthors, 2005: The ERA-40 Re-Analysis. Quart. J. Roy. Meteor. Soc., 131, 2961-3012.

Xie, P., and P. A. Arkin, 1997: Global precipitation: A 17-year monthly analysis based on gauge observations, satellite estimates, and numerical model outputs. Bull. Amer. Meteor. Soc., 78, 2539-2558.

Zheng, X. and E. A. B. Eltahir, 1998: The role of vegetation in the dynamics of West African monsoons. J. Climate, 11, 2078-2096.

\section{TELL YOUR COLLEAGUES!}

Our new simplified application form makes joining the AMS easier than ever!

Applications are now being accepted online at www.ametsoc.org. 